\title{
Impact of Preoperative Rectal Misoprostol on Blood Loss during and after Elective Cesarean Delivery: A Randomized Controlled Trial
}

\author{
Sitaula $S^{1}$, Uprety DK ${ }^{1}$, Thakur A ${ }^{1}$, Pradhan $T^{1}$ \\ ${ }^{1}$ Department of Obstetrics and Gynecology, BPKIHS, Dharan, Sunsari, Nepal.
}

Received: 12-Aug-2016; Accepted: 17-Dec-2016

\begin{abstract}
Aims: The aim of this study was to evaluate the effect of preoperative administration of rectal misoprostol onblood loss during and after elective cesarean delivery.

Methods: It was a randomized trial including 200 women, divided into two groups (group A and group B), who were planned for elective cesarean delivery and didn't have risk of postpartum hemorrhage (PPH). Group A received $400 \mu \mathrm{g}$ misoprostol per-rectal preoperatively and intravenous infusion of oxytocin after delivery as hospital protocol.Group B received only intravenous infusion of oxytocin. Primary outcome measureswere the estimated amount of intraoperative and postoperative ( 24 hours) blood loss and changes in hemoglobin levels 48 hours after delivery.
\end{abstract}

Results: Intraoperative and postoperative blood loss in rectal misoprostol and oxytocin group were significantly reduced in comparison to oxytocin only group. Mean blood loss in groupA was $326.9 \pm 116.2$ mlwhereas; in group B was $397.7 \pm 110.1 \mathrm{ml}$ with $\mathrm{p}$ value of $<0.001$ which was significant. The difference between preoperative and postoperative hemoglobin level after 48 hours was also significant $(1.10 \pm 0.51 \mathrm{vs} 1.35 \pm 0.49 \mathrm{~g} / \mathrm{dl}$ with $\mathrm{p}$ value $<0.001)$.

Conclusions: Preoperative rectal misoprostol was found to be an effective measure to reduce the intraoperative and postoperative blood loss during elective cesarean delivery.

Keywords: cesarean delivery;misoprostol; postpartum hemorrhage.

\section{INTRODUCTION}

PPH is a major cause of morbidity and mortality during childbirth, especially in low and middle income countries. ${ }^{1}$ The incidence of cesarean delivery is increasing and its average blood loss is double the amount lost during vaginal delivery. The major cause of postpartum anemia is blood loss at delivery.

Although many obstetric units use intravenous bolus or infusion of oxytocin to prevent uterine atony and blood loss during and after C-section, 10\%-40\% of women receiving oxytocin require additional uterotonic agents. ${ }^{2}$ Misoprostol, a prostaglandin E1 (PGE1) analogue, has potentuterotonic action, is cheap and stable at room temperature, and has a few adverse effects. The objective of this study was to randomly compare the effectiveness of oral misoprostol with intravenous syntocinon on blood loss during elective cesarean sections under regional anesthesia.

\section{CORRESPONDENCE}

Dr. Sarita Sitaula,

Department of Obstetrics and Gynecology,

BPKIHS, Dharan, Sunsari, Nepal.

Email: dr.sarita.sitaula@gmail.com.

Phone: +977-9842052514
Sixty pregnant women were randomized either to receive misoprostol 400 micrograms orally or syntocinon 10 IU intravenously during cesarean section. The primary outcome measure was intraoperative blood loss as estimated by physicians, and by values of preoperative and postoperative hemoglobin concentration and hematocrit. Demographic characteristics of the subjects and outcomes were compared using chi-square test for categorical and two-sample t-test for continuous data.

Baseline characteristics in terms of age, body weight, parity, gestational age and indications for cesarean section were similar in both groups. The estimated blood loss was $545 \mathrm{ml}$ (CI 476-614Misoprostol, a prostaglandin E1 (PGE1) analogue, has potentuterotonic action, is cheap and stable at room temperature, and has a few adverse effects.

The aim of the present study was to evaluate the efficacy and safety of rectal administration of $400 \mu \mathrm{g}$ of misoprostol with oxytocin in preventing uterine atony and blood loss compared to intravenous infusion of oxytocin in elective cesarean deliveries. 


\section{METHODS:}

It was a randomized control study conducted in Department of Obstetrics and Gynecology, BPKIHS, Dharan, from 2012 to 2013 after approval from Institutional Ethical Review Board (IRB). A total of 200 women who were admitted for elective cesarean delivery with period of gestation ranging from 37 weeks to 42 weeks who did not have any risk factors for PPH were enrolledafter informed consent. Patients having risk factors like polyhydramnios, uncontrolled Diabetes Mellitus, previous two or more cesarean deliveries, severe preeclampsia, multiple gestation, grand multipara, known coagulation disorder, cesarean delivery under general anesthesia, previous myomectomy, previous uterine rupture, abnormal placentation and sensitivity to misoprostol were excluded.

Sample size was calculated according to the study done by Milman $\mathrm{N}^{3}$ with Confidence level of $95 \%$ and Power of study $80 \%$ and the sample size was 80 in each arm. $20 \%$ was added for various errors and it came 100 in each arm.

The patients were randomly allocated into two groups using computer generated random table. Women in group A received total preoperative dose of $400 \mu \mathrm{g}$ misoprostol administered as two tablets each $200 \mu \mathrm{g}$, along with $20 \mathrm{IU}$ of oxytocin in $500 \mathrm{ml}$ of ringer lactate via infusion after delivery while women assigned to group B received only 20 IU of oxytocin after delivery. Misoprostol tablets were inserted rectally after giving spinal anesthesia and inserting Foley catheter.

C-section was performed under spinal anesthesia. Assessment of blood loss was started immediately after the uterine incision. Liquor and blood were collected by suction catheter separately. The volume of blood loss in $\mathrm{C}$-section was assessed by the standard procedure. The tetras used during operation were weighed before and after surgery. One gram of weight difference was taken equivalent to one milliliter of blood. One fist full of clot was equivalent of $500 \mathrm{ml}$ of blood. Total blood loss was then calculated. Additional oxytocics were used if required. Patients were followed up to 48 hours following delivery. Blood loss was measured up to 24 hours postoperatively, if any patient was found to have more bleeding. All the pads used were weighed before and after use. Total blood loss in 24 hours was calculated. PPH was considered when blood loss exceeded $1000 \mathrm{ml}$.
Then data were collected according to the preformat and entered into Excel 2013 and analyzed with SPSS version 21. The $\mathrm{T}$ tests, Mann-Whitney $\mathrm{U}$ test, chi square test were used to compare variables as appropriate. Results were reported as mean \pm SD or number (percentage). The $\mathrm{p}$ value $<0.05$ was considered statistically significant.

\section{RESULTS}

There were a total of 12,900 deliveries during the study period. The total number of C-section was 3768 amongst which 365 were elective $\mathrm{C}$-section. Among the elective $\mathrm{C}$-section, two hundred patients meeting the inclusion criteria were enrolled in the study and their demographic information is shown (Table 1).It was found that intraoperative and postoperative blood loss was significantly reduced with the use of preoperative per-rectal misoprostol along with oxytocin as compared to intravenous oxytocin only. Mean blood loss of $326.9 \pm 116.2 \mathrm{ml}$ and $397.7 \pm 110.1$ $\mathrm{ml}$ in group A and group B respectively was seen with $p$ value of $<0.001$ (Table 2). The difference between preoperative and postoperative hemoglobin level after 48 hours of C-section was also significant (Table 3).

There were no losses to follow up and patients were not discharged till 48 hours postpartum.

In this study only one patient in control group had $\mathrm{PPH}$ and required blood transfusion along with additional oxytotics, and two patients developed fever in misoprostol group which were statistically not significant.

Table 1. Demographic and obstetrics characteristics of the patient $(n=200)$.

\begin{tabular}{|llll|}
\hline Characteristics & $\begin{array}{l}\text { Group A } \\
(\mathbf{n}=\mathbf{1 0 0})\end{array}$ & $\begin{array}{l}\text { Group B } \\
(\mathbf{n}=100)\end{array}$ & p value \\
\hline Age (years) & $27.72 \pm 2.59$ & $27.07 \pm 2.69$ & 0.84 \\
Gravidity & $2.2 \pm 0.5$ & $2.1 \pm 0.6$ & 0.71 \\
$\begin{array}{l}\text { Gestational age } \\
\text { (weeks) }\end{array}$ & $38.9 \pm 0.9$ & $38.9 \pm 0.9$ & 0.82 \\
Birth weight (kg) & $3.2 \pm 0.3$ & $3.2 \pm 0.3$ & 0.111 \\
Preop Hb (gm/dl) & $11.3 \pm 0.9$ & $11.4 \pm 0.9$ & 0.24 \\
\hline
\end{tabular}

Table 2. Primary outcomes.

\begin{tabular}{|lllll|}
\hline & $\begin{array}{l}\text { Group } \\
\text { A }\end{array}$ & $\begin{array}{l}\text { Group } \\
\text { B }\end{array}$ & p value & Remarks \\
\hline $\begin{array}{l}\text { Intraoperative } \\
\text { mean blood }\end{array}$ & $326.9 \pm$ & $397.7 \pm$ & $<0.001$ & Significant \\
loss(ml) & 116.2 & 110.1 & & \\
\hline
\end{tabular}


Table 3. Differences between Preoperative and

postoperative hemoglobin.

\begin{tabular}{|lllll|}
\hline & Group A & Group B & p value & Remarks \\
\hline $\begin{array}{l}\text { Preop Hb } \\
\text { (g/dl) }\end{array}$ & $11.3 \pm 0.9$ & $11.4 \pm 0.9$ & 0.24 & NS \\
$\begin{array}{l}\text { Postop Hb } \\
\text { (g/dl) }\end{array}$ & $10.2 \pm 0.8$ & $10.1 \pm 0.8$ & 0.30 & NS \\
$\begin{array}{l}\mathrm{Hb} \\
\text { difference } \\
(\mathrm{g} / \mathrm{dl})\end{array}$ & $1.10 \pm 0.51$ & $1.35 \pm 0.49$ & $<$ & Significant \\
\hline
\end{tabular}

\section{DISCUSSION}

The present study was carried out to reduce the need of rescue uterotonics and reduce blood loss. In countries where women have severe anemia during pregnancy because of nutritional and environmental factors, even a reduction of relatively smaller amount of blood loss could be relevant clinically. ${ }^{4}$ The proper management of PPH is an essential component of obstetric care and a necessary step to reduce worldwide maternal mortality.

Misoprostol has been used for more than a decade for prophylaxis and control of PPH after vaginal birth but there is a lack of consensus about the optimum dose and the best route of administration. Nevertheless, misoprostol has several advantages over oxytocin, particularly with respect to cost, ease of administration (via several routes), adverse effect profile, and potency. Rectal administration of misoprostol has been used for prevention of PPH after vaginal delivery with encouraging results. ${ }^{5,6}$ Oxytocin is used routinely during delivery to prevent uterine atony and excessive uterine bleeding. Despite its effectiveness, $10-40 \%$ of women require additional doses of uterotonics to control uterine atony and bleeding. Rectally administered misoprostol is associated with slower absorption, lower peak levels, and reduced adverse effects when compared with the oral and sublingual routes, ${ }^{7}$ therefore, it was the preferred route of administration in the present study. Doses ranging from $200 \mu \mathrm{g}$ to $1000 \mu \mathrm{g}$ were previously used in the literature. ${ }^{7,8}$

In this study, $400 \mu \mathrm{g}$ of misoprostol was administered rectally after catheter insertion. This approach was not only for convenience but also to give a few minutes for drug absorption and action to occur. Oxytocin was given to participants in both the groups because the objective of the present study was to test the additional value of misoprostol in further reducing blood loss rather than to directly compare the two drugs. The safety of giving misoprostol at a dose of $400 \mu \mathrm{g}$ while the fetus was still in utero was a key concern.

Pharmacokinetic studies done by Khan et al. ${ }^{7}$ found that rectal administration of $600 \mu \mathrm{g}$ of misoprostol was advantageous for routine management of the third stage of labor as compared to oral administration of $600 \mu \mathrm{g}$ because the area under the curve (integral of concentration and time graph) for rectal misoprostol was higher than that for oralmisoprostol, resulting in a longer duration of action.

Rectal administration of misoprostol was investigated in a study by Lokugamage et al, ${ }^{9}$ who successfully treated seven cases of PPH after cesarean delivery with $800 \mu \mathrm{g}$ of rectal misoprostol.

In the present study, no problems were encountered with rectal administration of misoprostol during the operation. Metallic taste in the mouth and nausea, the commonly reported problems after sublingual and oral $^{10,11}$ administration, were avoided.

The result of present study showed significant reduction of intraoperative and postoperative blood loss in rectal misoprostol and oxytocin group in comparison to oxytocin only group. Mean blood loss in group A was $326.9 \pm 116.2 \mathrm{ml}$ whereas ingroup B was $397.7 \pm 110.1 \mathrm{ml}$ with $\mathrm{p}$ value of $<0.001$ which was significant.

These results were compared with Vimala et al, ${ }^{10}$ who reported a similar reduction in intraoperative blood loss after a sublingual administration of $400 \mu \mathrm{g}$ of misoprostol compared to intravenous oxytocin infusion (819 vs $974 \mathrm{~mL}$, respectively; $\mathrm{p}<0.004$ ), and studies by Zhao et $\mathrm{al}^{12}$, who used $600 \mu \mathrm{g}$ of oral misoprostol and oxytocin infusion $(212 \pm 56$ vs $345 \pm 64.7 \mathrm{ml}$, respectively, $\mathrm{p}<0.01)$. There was a significant change in the mean hemoglobin concentration postoperatively in both the groups with $p$ value of $<0.001$. The difference, not only in the dose, route, and time of administration of the intervention and control drugs, but also in the method of assessing blood loss may be responsible for different conclusions of these studies.

This study also showed that there was a significant hemoglobin difference between the two groups. Mean hemoglobin difference in group A was $1.10 \pm 0.51 \mathrm{~g} / \mathrm{dl}$ whereas in group B was $1.35 \pm 0.49 \mathrm{~g} / \mathrm{dl}$ with $\mathrm{p}$ value of $<0.001$. 
Our study, along with the available literature on rectally administered misoprostol, illustrates that rectal misoprostol seems to be effective in reducing the likelihood of intrapartum and $\mathrm{PPH}$ after cesarean delivery at a dose of 400 micrograms when given preoperatively.

Our country is a developing country and many centers do not have facilities for proper storage of oxytocin. As for its efficacy, oxytocin needs to be stored at a temperature of two to eight degree Celsius, but many of our centers do not have refrigeration facilities. Hence, misoprostol seems to be a better option for our low resource settings. Misoprostol is cheaper as compared to oxytocin and its administration is much easier with no special training required to administer it. Also, it doesn't require intramuscular administration like oxytocin and the results are similar to those of oxytocin use with an acceptable safety profile.

\section{LIMITATIONS OF THE STUDY}

Exclusion of high risk cases for $\mathrm{PPH}$ was the limitation of the present study. Also blinding couldn't be done due to lack of placebo.

\section{CONCLUSIONS}

This study showed that misoprostol used perrectally before Cesarean Section not only reduces the need for uterotonics but also reduces the intraoperative blood loss and change in hemoglobin level.

\section{REFERENCES}

1. Chaudhuri P, Banerjee GB, Mandal A. Rectally administered misoprostol versus intravenous oxytocin infusion during cesarean delivery to reduce intraoperative and postoperative blood loss. Int J Gynaecol Obstet. 2010;109:25-9.

2. Acharya G, Al-Sammarai MT, Patel N, Al-Habib A, Kiserud T. A randomized, controlled trial comparing effect of oral misoprostol and intravenous syntocinon on intra-operative blood loss during cesarean section. Acta Obstet Gynecol Scand. 2001;80:245-50.

3. Milman N. Postpartum anemia I: definition, prevalence, causes, and consequences. Ann Hematol.2011;90:1247-53.

4. Prendiville W, Elbourne D, Chalmers I. The effects of routine oxytocic administration in the management of the third stage of labour: an overview of the evidence from controlled trials. Br J Obstet Gynaecol. 1988;95:3-16.

5. Nasr A, Shahin AY, Elsamman AM, Zakherah MS, Shaaban OM. Rectal misoprostol versus intravenous oxytocin for prevention of postpartum hemorrhage. Int $\mathrm{J}$ Gynecol Obstet.2009;105:244-47.

6. Parsons SM, Walley RL, Crane JMG, Matthews K, Hutchens D. Rectal misoprostol versus oxytocin in the management of the third stage of labour. J Obstet Gynaecol Can. 2007;29:71118 .
7. Khan RU, El-Refaey H. Pharmacokinetics and adverse-effect profile of rectally administered misoprostol in the third stage of labor. Obstet Gynecol. 2003;101:968-74.

8. Tang OS, Ho PC. The pharmacokinetics and different regimens of misoprostol in early first-trimester medical abortion. Contraception. 2006 ;74:26-30.

9. Lokugamage AU, Sullivan KR, Niculescu I, Tigere P, Onyangunga $\mathrm{F}$, El Refaey $\mathrm{H}$ et al. A randomized study comparing rectally administered misoprostol versus Syntometrine combined with an oxytocin infusion for the cessation of primary post partum hemorrhage. Acta Obstet Gynecol Scand. 2001;80:835-9.

10. Vimala N, Mittal S, Kumar S. Sublingual misoprostol versus oxytocin infusion to reduce blood loss at cesarean section. Int J Gynaecol Obstet.2006;92:106-10.

11. Lokugamage AU, Paine M, Bassaw-Balroop K, Sullivan KR, Refaey HE, Rodeck CH. Active management of the third stage at caesarean section: a randomised controlled trial of misoprostol versus syntocinon. Aust N Z J Obstet Gynaecol. 2001;41:411-4

12. Zhao Y, Li X, Peng Y. Clinical study on reduction of postpartum bleeding in cesarean section by misoprostol. Zhonghua Fu Chan Ke Za Zhi.1998;33:403-5. 


\title{
A Profile of Patients with Molar Pregnancy
}

\author{
Bhatt $\mathbf{R}^{\mathbf{1}}$, Rijal $\mathbf{P}^{\mathbf{1}}$, Pradhan $\mathrm{T}^{\mathbf{1}}$, Chhetri $\mathbf{S}^{\mathbf{1}}$, Rai $\mathbf{R}^{\mathbf{1}}$, Uprety $\mathbf{D}^{\mathbf{1}}$ \\ Department of Obstetrics and Gynecology, B.P. Koirala Institute of Health Sciences (BPKIHS), Dharan, Nepal.
}

Received: 29-Nov-2016; Accepted: 17-Dec-2016

\begin{abstract}
Aims: This study was done to determine the incidence, modes of presentation and prognosis of molar pregnancy at B. P. Koirala Institute of Health Sciences.

Methods: This was a prospective study done among patients with molar pregnancy admitted at BPKIHS from January 2010 to January 2011. The study was conducted after ethical clearance from Institutional Ethical Review Board of BPKIHS. Written informed consent was taken for enrollment in the study. Baseline information like age, address, race and patient's presenting complaints, period of gestation and serial serum beta human chorionic gonadotropin ( $\beta$ hCG) were collected and analyzed after entering in excel sheet.
\end{abstract}

Results: Total 48 cases of molar pregnancy were diagnosed during the study period. The incidence of molar pregnancy was found to be 5.58 per 1000 deliveries. The most common mode of presentation was per vaginal bleeding i.e. in $64.58 \%$ of cases Majority of the patients were in the age group of $20-34$ years $(62.5 \%)$. Mean time for normalization of $\beta$ hCG after suction evacuation was 10.19 weeks.

Conclusions: Molar pregnancy is a pregnancy related problem which most commonly presents with per vaginal bleeding during first and second trimester. Most of the patients are treated with suction and evacuation but some develop persistent gestational trophoblastic disease.

Keywords: $\beta$ hCG; molar pregnancy.

\section{INTRODUCTION}

Hydatidiform moles are abnormal conceptions with incidence of 1/500-1000 pregnancies. Complete moles are usually diploid and developmentally androgenic, demonstrating hydropic chorionic villi and trophoblastic hyperplasia. Partial moles are usually paternally derived triploid conceptions in which embryonic development occurs in association with trophoblastic hyperplasia.'Partial hydatidiform moles are characterized by chorionic villi of varying size with focal hydatidiform swelling, cavitations, trophoblastic hyperplasia, marked villous scalloping and prominent stromal trophoblastic inclusions. Complete hydatidiform moles exhibit characteristic swelling and trophoblastic hyperplasia and have propensity to malignancy. ${ }^{2}$

The classic presenting symptoms and findings of hydatidiform mole include vaginal bleeding, anemia, excessive uterine enlargement, hyperemesis gravidarum, hyperthyroidism, trophoblastic emboli and theca lutein cysts associated with remarkably elevated $\beta$ hCG titres. ${ }^{3,4}$

\section{CORRESPONDENCE}

Dr. Rabindra Dev Bhatt

Department of Obstetrics and Gynecology

BPKIHS, Dharan, Sunsari, Nepal

Email: rabindrabhatt364@gmail.com

Phone: +977-9842038782
After evacuation it should be ensured that $\beta$ hCG levels remain undetectable. If patients want to conceive, they are generally advised not to become pregnant again until after the first six months of follow up and are given reliable contraception. After spontaneous resolution, the patient is subsequently seen monthly for six months. ${ }^{5-7}$

Most gestational trophoblastic neoplasia (GTN) cases are diagnosed clinically using hormonal evidence of persistent trophoblastic tissue. Tissue is infrequently available for pathologic diagnosis. So GTN is diagnosed on the basis of rising $\beta$ hCG values or a persistent plateau of $\beta \mathrm{hCG}$ values for at least three weeks. ${ }^{8-13}$

Since BPKIHS is a tertiary care centre of Eastern Nepal, patients coming here represent the population of Eastern Nepal. The clinical profile of patients with molar pregnancy has not been studied in this area in past, this study was conducted to find out the the clinico-epidemiological profile of molar pregnancy in Eastern Nepal.

\section{METHODS}

This was a prospective study done among patients with molar pregnancy admitted at BPKIHS from January 2010 to January 2011. The study was 